\title{
Plasma Cholesterol Metabolism in End-Stage Renal Disease Difference between Treatment by Hemodialysis or Peritoneal Dialysis
}

\author{
Hans Dieplinger, Patricia Y. Schoenfeld, and Christopher J. Fielding \\ Cardiovascular Research Institute, Departments of Physiology and Medicine, and University of California \\ Renal Center, San Francisco General Hospital, University of California, San Francisco, California 94143
}

\begin{abstract}
Plasma cholesterol metabolism was investigated in normotriglyceridemic patients with end-stage renal disease treated by hemo- or continuous ambulatory peritoneal dialysis (CAPD), and compared with that in a control group with normal renal function. A reversed net transport of free cholesterol from plasma to cultured fibroblasts, as well as greatly reduced levels of plasma cholesterol esterification and cholesterol ester transfer rates to low and very low density lipoproteins (LDL and VLDL), was found in the hemodialysis group compared to the controls. The LDL and VLDL contained increased amounts of free cholesterol and inhibited cholesterol ester transfer when recombined with control plasma. The LDL triglyceride content was doubled in the hemodialysis group, whereas cholesterol esters were decreased. Patients treated by CAPD, in marked contrast, had cholesterol metabolic rates that were within the normal range, as well as normal lipoprotein composition.
\end{abstract}

\section{Introduction}

There is a common pattern of abnormal plasma cholesterol metabolism in several groups of human subjects who are at increased risk for atherosclerotic vascular disease. These include non-insulin-dependent (type II) diabetics and those with several welldefined hyperlipidemias of genetic origin $(1,2)$. This pattern is defined by a reduction in the rate of transport of cholesterol from cell membranes to the abnormal plasma, and an inhibition in the plasma of the transfer of cholesteryl esters to low and very low density lipoproteins (LDL and VLDL). The same patients show a decreased ratio of high density to low density lipoproteins (HDL/LDL) $(1,3)$. The diabetics also show characteristic abnormalities of plasma lipoprotein composition, most notably an increase in the ratio of free cholesterol to phospholipid in VLDL and LDL (4).

Patients with chronic renal insufficiency and end-stage renal disease (ESRD) ${ }^{1}$ form an additional large group with a welldefined, high risk of vascular disease $(5,6)$. This risk may or may not be accelerated by dialysis treatment per se $(7,8)$. Like the other groups mentioned above, renal patients show a low HDL/LDL ratio (9).

Received for publication 5 November 1984 and in revised form 9 October 1985.

1. Abbreviations used in this paper: apo, apoprotein; BUN, blood urea nitrogen; CAPD, continuous ambulatory peritoneal dialysis; ESRD, endstage renal disease; LCAT, lecithin:cholesterol acyltransferase.

J. Clin. Invest.

(C) The American Society for Clinical Investigation, Inc. $0021-9738 / 86 / 04 / 1071 / 13 \quad \$ 1.00$

Volume 77, April 1986, 1071-1083
Additionally, about one-third of ESRD patients have plasma triglyceride levels that are significantly increased $(10,11)$, and in these patients the concentration of circulating remnants of dietary particles (chylomicrons) as well as of plasma apolipoprotein $\mathrm{E}$ is also increased (12). The composition of HDL has been studied in some detail (13). Apoprotein (apo) A-I, the major apoprotein of HDL, has been reported as normal (11) and decreased (9) in patients on hemodialysis.

Less is known about the plasma lipid metabolism of patients on continuous ambulatory peritoneal dialysis (CAPD) $(14,15)$. There is contradictory information concerning HDL-cholesterol levels in this group, which have been reported to rise (16) or fall (17) during dialysis. Other reports describe a total plasma cholesterol and triglyceride increase in patients treated by CAPD (18). Uremic patients (19), but not those in other groups $(1,2)$, have also been reported to have lower rates of cholesterol esterification in plasma.

The purpose of the present study was to investigate the parameters of plasma cholesterol metabolism in patients with ESRD treated by hemodialysis, and to compare these results with values obtained from patients with similarly impaired renal function treated by CAPD and from a control group of comparable age with normal renal function.

\section{Methods}

Patient selection. Patients on center-based hemodialysis or CAPD were selected from the patient population of the University of California Renal Center at San Francisco General Hospital. All patients were clinically stable and had been treated for ESRD for at least 3 mo, with a range of 3-99 mo. Patients 19 and 21 had received hemodialysis prior to CAPD. The chronic dialysis population from which these patients were selected includes 45 patients on hemodialysis, and 17 patients on peritoneal dialysis. The incidence of hypertriglyceridemia in the hemodialyzed patients was $34 \%$, whereas $17 \%$ had an elevated total plasma cholesterol concentration. The CAPD patients, however, had both elevated plasma triglyceride and higher cholesterol concentrations in $47 \%$ of patients, confirming earlier reports of a greater incidence of lipid composition abnormalities in this patient group $(17,18)$. Other than the selection criteria indicated below, those patients selected for study were representative of the dialysis population as a whole. Of the hemodialysis and CAPD populations $15 \%$ and $29 \%$, respectively, were diabetic. Patients were excluded from this study for the following reasons: ( $a$ ) diabetes mellitus (with the exception of one insulin-treated patient [patient 16] in the CAPD group); (b) cigarette smoking; (c) known or suspected liver disease, including chronic hepatitis B surface antigen carrier state; $(d)$ elevations of total plasma cholesterol or triglyceride levels. Of 21 patients studied 11 were receiving anabolic agents for treatment of anemia, and 11 patients were on antihypertensive agents for control of dialysis-resistent hypertension (Table I). The doses of the anabolic agents prescribed for those patients were as follow: testosterone enanthate, $4 \mathrm{mg} / \mathrm{kg} \cdot \mathrm{wk}$; nandrolone decanoate, $2-3 \mathrm{mg} / \mathrm{kg} \cdot \mathrm{wk}$; and halotestin, $0.4 \mathrm{mg} / \mathrm{kg} \cdot \mathrm{d}$.

Hemodialysis patients were treated three times weekly for 3-4 h using hollow fiber dialyzers with an acetate and glucose $(200 \mathrm{mg} / \mathrm{dl})$ containing 


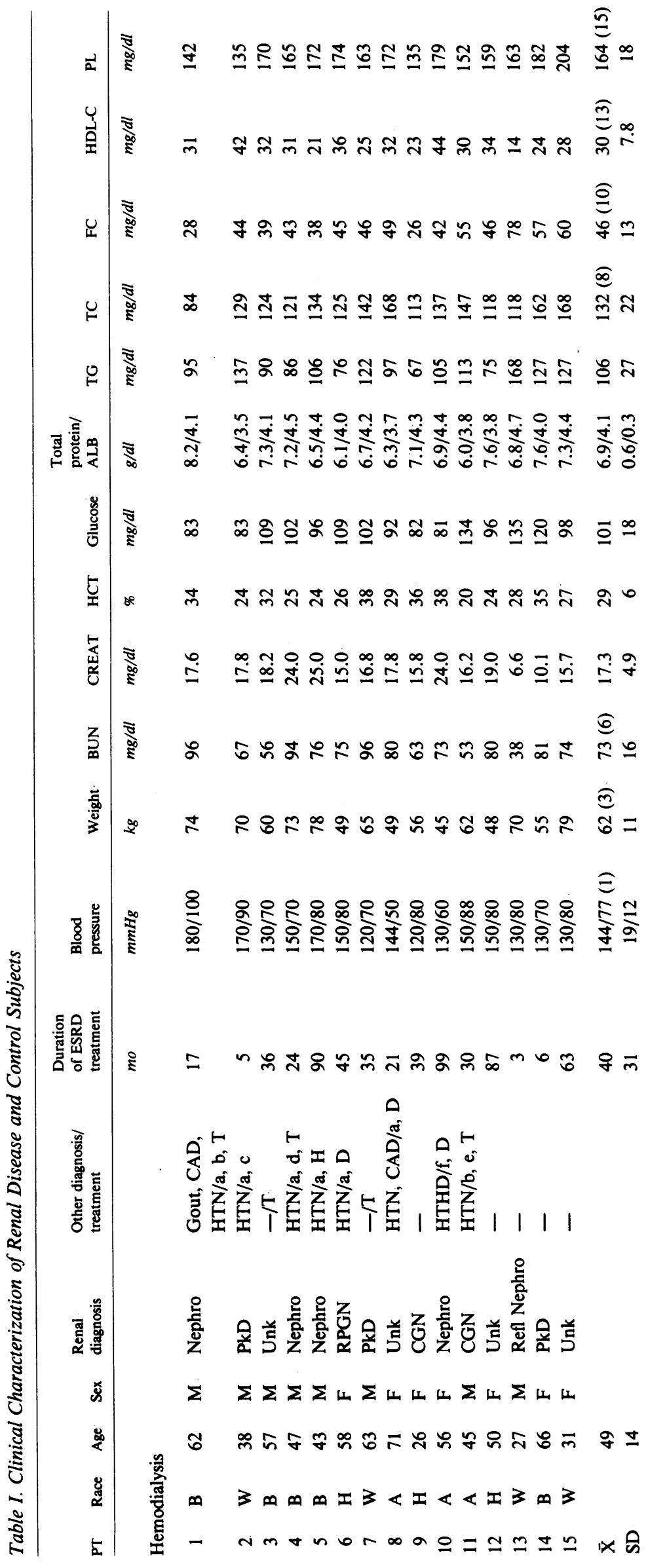




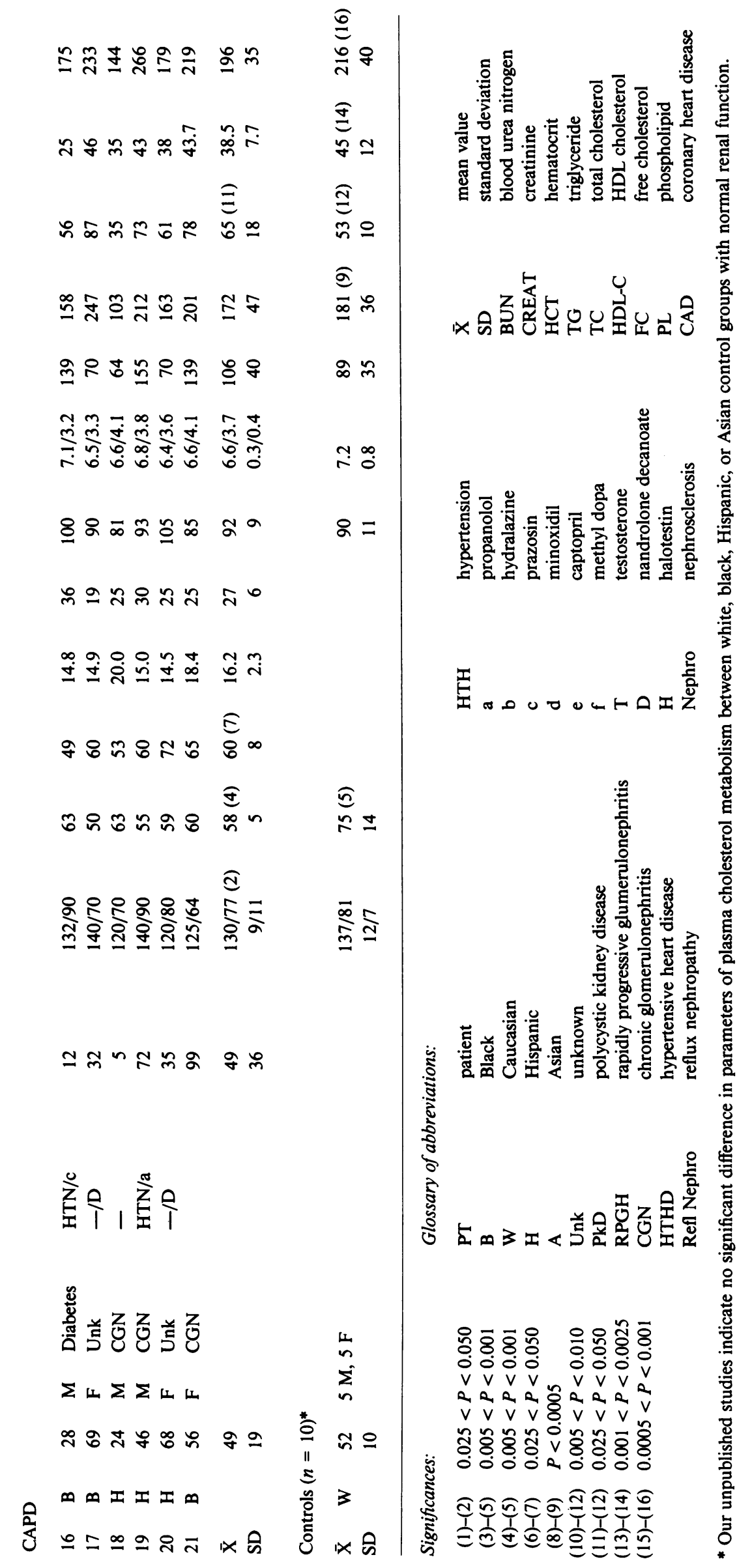


dialysate. CAPD patients performed four exchanges daily using variable concentrations of dialysate dextrose. To assess adequacy of dialysis treatment, midweek predialysis values for blood urea nitrogen (BUN), creatinine, hematocrit, and random glucose were obtained in the hemodialysis patients. Routine monthly values for the CAPD patients are listed. Blood pressure control in each patient is estimated from the usual predialysis or routine monthly value. The weight for each patient is the postdialysis or "dry" weight, or routine monthly weight. Nutritional status was assessed by weight and serum total protein and albumin (Table I). Hemodialysis patients were prescribed diets containing $1.0 \mathrm{~g}$ of protein and $35 \mathrm{kcal} / \mathrm{kg}$ of body weight. CAPD patients were prescribed 1.2-1.5 $\mathrm{g}$ of protein $/ \mathrm{kg}$ and $25 \mathrm{kcal} / \mathrm{kg}$ to adjust for protein loss into and glucose absorption from the dialysate, respectively. Control subjects matched for sex, age, plasma glucose, and total triglyceride levels were drawn from medical center staff.

Blood was drawn from all subjects after an overnight fast and, in the case of the hemodialysis group, immediately before dialysis and heparinization. CAPD patients were studied without interruption of dialysis. Blood was collected into $1 / 20$ vol of $0.2 \mathrm{M}$ sodium citrate solution (pH 7.5), immediately cooled in ice, and plasma was obtained by centrifugation at $3^{\circ} \mathrm{C}(1,500 \mathrm{~g}, 30 \mathrm{~min})$. The plasma was then used directly in the assays described below.

Determination of cholesterol net transport. The direction and magnitude of cholesterol net transport between plasma and cultured normal skin fibroblasts was carried out with an assay previously described (1, 20). Human preputial skin fibroblasts were cultured to $75 \%$ confluence in 6-cm plastic dishes (Falcon Labware, a division of Becton, Dickinson \& Co., Oxnard, CA) containing 10\% vol/vol fetal calf serum in Dulbecco's modified Eagle's medium. Dishes containing 8-10 $\mu \mathrm{g}$ of cell cholesterol were incubated in $3 \mathrm{ml}$ of plasma ( $1.2 \% \mathrm{vol} / \mathrm{vol})$ in phosphate-buffered saline solution which had been depleted of fibrinogen by immunoaffinity chromatography. 1-ml samples of medium were taken from pentuplicate dishes before and after $60 \mathrm{~min}$ of incubation at $37^{\circ} \mathrm{C}$, and placed into methanol for analysis of free and esterified cholesterol. The decrease in medium free cholesterol was compared with that obtained from empty dishes containing the same plasma medium. The contribution of cellular cholesterol to the total esterified during the incubation (cell to plasma cholesterol net transport) was determined as the difference between the values from cell containing and empty dishes. Quintuplicate dishes of cells that had been incubated with the medium and unincubated dishes were washed four times with phosphate-buffered saline, and the cells were dissolved in $0.1 \mathrm{M} \mathrm{NaOH}$ and extracted with chloroform and methanol for analysis of free and esterified cholesterol.

Determination of cholesterol esterification rate. The rate of esterification of cholesterol in plasma was determined from the rate of decrease in free cholesterol content in plasma diluted fivefold with $0.15 \mathrm{M} \mathrm{NaCl}$ containing $0.01 \mathrm{M}$ Tris- $\mathrm{HCl}, 1 \mathrm{mM}$ disodium EDTA, $\mathrm{pH}$ 7.5. Incubation was for $60 \mathrm{~min}$ at $37^{\circ} \mathrm{C}(1)$. Free cholesterol in pentuplicate initial and final plasma samples was measured fluorimetrically, after extraction of plasma lipids with chloroform and methanol (21).

Cholesterol esterification in plasma mediated by lecithin:cholesterol acyltransferase (LCAT) was also measured with an assay medium of $\left[{ }^{3} \mathrm{H}\right]$ cholesterol egg lecithin liposomes prepared by the French press method (22). Cholesterol and lecithin were dispersed at a molar ratio of 0.25 and incorporated into a medium also containing $10 \mathrm{mg} / \mathrm{ml}$ recrystallized human serum albumin (pH 7.4) and apo A-I (the protein cofactor of LCAT) $(25 \mu \mathrm{g} / \mathrm{ml})$. The final concentration of lecithin liposomes in the assay was $0.4 \mathrm{mg} / \mathrm{ml}$. Plasma (1-5 $\mu \mathrm{l})$ was added to this medium and the rate of production of labeled cholesteryl ester determined over a time course of $5 \mathrm{~min}$ at $37^{\circ} \mathrm{C}$. Labeled cholesteryl esters were separated from labeled free cholesterol at the end of the incubation by extraction of the assay medium with chloroform and methanol, and thin-layer chromatography of portions of the chloroform phase on silica gel layers on glass plates developed in hexane/diethyl ether/acetic acid (83:16:1 $\mathrm{vol} / \mathrm{vol})$. Radioactivity was determined by liquid scintillation spectrometry.

Determination of cholesteryl ester transfer to VLDL and $L D L$. In the absence of cholesteryl ester synthesis by LCAT, the decrease in HDL cholesteryl ester represents the rate of transfer of cholesteryl ester to VLDL and LDL $(23,24)$. Plasma was diluted twofold with saline containing Tris and EDTA and brought to $1.5 \mathrm{mM} 5,5^{\prime}$-dithiobis(2-nitrobenzoic acid), an inhibitor of plasma LCAT activity. Plasma samples taken before and after incubation $\left(60 \mathrm{~min}, 36^{\circ} \mathrm{C}\right)$ were mixed with 0.05 vol of $2 \mathrm{M} \mathrm{MgCl}_{2}$ and the same volume of dextran sulfate solution (Pharmacia, Uppsala, Sweden; average molecular weight $5 \times 10^{5} ; 10 \mathrm{mg} / \mathrm{ml}$ ) to precipitate VLDL and LDL. The precipitate was removed by centrifugation $(150 \mathrm{~g}, 20 \mathrm{~min})$, and pentuplicate samples of supernatant were extracted into chloroform and methanol and their cholesteryl ester content determined.

Determination of cholesteryl ester transfer was also performed, under similar conditions as for the cholesterol transport assay, in order to show whether the presence of cultured cells interferes with the transfer to cholesteryl esters to LDL and VLDL. In detail, plasma depleted of fibrinogen was diluted twofold with phosphate-buffered saline and incubated as described for the transport assay. Samples taken before and after the incubation were treated with $2 \mathrm{M} \mathrm{MgCl}_{2}$ and dextran sulfate, as described for the regular cholesteryl ester transfer assay.

The level of cholesteryl ester transfer activity in plasma was also determined as the mass of $\left[{ }^{3} \mathrm{H}\right]$ cholesteryl ester in HDL transferred to unlabeled centrifugally isolated LDL in an assay medium containing HDL ( $100 \mu \mathrm{g} / \mathrm{ml}$ cholesteryl ester), LDL ( $600 \mu \mathrm{g} / \mathrm{ml}$ cholesteryl ester), $10 \mathrm{mg} / \mathrm{ml}$ recrystallized human serum albumin ( $\mathrm{pH} 7.4$ ), $1.4 \mathrm{mM} \mathrm{5,5^{ \prime } -}$ dithiobis(2-nitrobenzoic acid) and plasma, finally diluted 1:10 (20 $\mu \mathrm{l})$ (25). Incubation was carried out over $3 \mathrm{~h}$ at $37^{\circ} \mathrm{C}$, during which time the reaction was linear. At the end of the incubation period, LDL was isolated by centrifugal flotation, using the 2-ml adaptors of a 40.3 Beckman ultracentrifuge rotor (Beckman Instruments, Inc., Fullerton, CA) for $24 \mathrm{~h}$ at 38,000 rpm. The upper LDL layer was recovered by slicing and extracted with chloroform and methanol; labeled cholesteryl ester was isolated and quantified by thin-layer chromatography and liquid scintillation spectrometry, as described above.

Fractionation of plasma lipoproteins. For the separation of the different lipoprotein fractions, a combination of heparin-agarose chromatography, preparative ultracentrifugation, and immunoaffinity chromatography was used, as previously described in detail (4). Fasting plasma $(5 \mathrm{ml})$ from ESRD or control subjects was passed at $4^{\circ} \mathrm{C}$ through a column $(1.5 \times 20 \mathrm{~cm})$ of heparin-agarose (Pharmacia Fine Chemicals, Piscataway, NJ) which had been equilibrated with $0.15 \mathrm{M} \mathrm{NaCl}, 1 \mathrm{mM}$ EDTA, $\mathrm{pH}$ 7.4. Nonadsorbed proteins were eluted and fractions containing detectable protein were pooled. The column was then washed with 10 column volumes of saline-EDTA, and the adsorbed lipoproteins eluted with $3 \mathrm{M} \mathrm{NaCl}, 1 \mathrm{mM}$ EDTA, $\mathrm{pH} 7.4$, and then dialyzed against saline-EDTA. Recovery of plasma proteins and lipids from chromatography was in both cases $>98 \% \mathrm{wt} / \mathrm{wt}$. The lipoproteins were either mixed with the nonadsorbed fraction of plasma for studies on the effects of the adsorbed lipoproteins (LDL and VLDL containing apo E) (4) on plasma cholesterol metabolism, or were further fractionated by ultracentrifugal flotation for more detailed chemical analysis. Centrifigation was for 18 $\mathrm{h}$ at $35,000 \mathrm{rpm}$ and $4^{\circ} \mathrm{C}$, at a solvent density of $1.019 \mathrm{~g} / \mathrm{ml}$. In this way, a VLDL fraction containing apo $\mathrm{E}(d<1.019 \mathrm{~g} / \mathrm{ml})$ and an $\mathrm{LDL}$ fraction $(d>1.019 \mathrm{~g} / \mathrm{ml})$ were obtained from the lipoproteins adsorbed to heparinagarose, and a VLDL fraction $(d<1.019 \mathrm{~g} / \mathrm{ml})$ and a fraction containing HDL $(d>1.019 \mathrm{~g} / \mathrm{ml})$, together with other remaining plasma proteins, were obtained from the nonadsorbed pool. HDL were then prepared by passing the nonadsorbed fraction $(d>1.019 \mathrm{~g} / \mathrm{ml})$ of plasma from heparin-agarose affinity chromatography through an immunoaffinity column consisting of agarose covalently complexed with specific anti-apo A-I antibodies raised to pure human apo A-I in rabbits. After the column was washed with 5 vol of saline-EDTA, bound HDL were eluted with 3 $M N$ NaSCN and dialyzed under vacuum against saline-EDTA to the original volume. Plasma was depleted of its apo $\mathrm{E}$ by passing $0.8 \mathrm{ml}$ through a column $(1 \times 20 \mathrm{~cm})$ of immobilized anti-apo E equilibrated with 0.15 $\mathrm{M} \mathrm{NaCl} / 1 \mathrm{mM} \mathrm{Na} 2$ EDTA, pH 7.0, and used in the assay of cholesterol transport as described above (2). The removal of apo $\mathrm{E}$ was confirmed 
Table II. Plasma Apoprotein Levels

in Renal Disease and Control Subjects

\begin{tabular}{cccc}
\hline & Hemodialysis & Controls & CAPD \\
\hline $\begin{array}{c}\text { Apo A-I } \\
(m g / d l)\end{array}$ & $\begin{array}{c}102 \pm 17 \\
(P<0.0005)\end{array}$ & $163 \pm 23$ & $123 \pm 20$ \\
$\begin{array}{c}\text { Apo A-II } \\
(m g / d l)\end{array}$ & $34.8 \pm 6.5$ & $36.4 \pm 2.0$ & $36 \pm 4$ \\
$\begin{array}{c}\text { Apo B } \\
(m g / d l)\end{array}$ & $89 \pm 14$ & $98 \pm 32$ & $94 \pm 8$ \\
$\begin{array}{c}\text { Apo D } \\
(m g / d l)\end{array}$ & $6.7 \pm 1.3$ & $5.6 \pm 1.2$ & $9.5 \pm 1.0$ \\
$\begin{array}{c}\text { Apo E } \\
(m g / d l)\end{array}$ & $6.8 \pm 0.8$ & $7.3 \pm 1.6$ & $(P<0.0005)$ \\
Apo A-I/Apo B & $1.15 \pm 0.18$ & $1.7 \pm 0.6$ & $1.3 \pm 0.9$ \\
& $(0.005<P<0.010)$ & \\
\hline
\end{tabular}

Values represent means \pm standard deviation from 15 hemodialysis, 6 peritoneal dialysis, and 10 control subjects.

by radial immunodiffusion. The lipid composition of all lipoprotein fractions was analyzed as described below.

Lipid and lipoprotein analysis. Apolipoproteins A-I, A-II, B, D, and E were determined by radial immunoassay with precisions of $2.5 \%, 5.8 \%$, $4.0 \%, 3.2 \%$, and $2.5 \%$, respectively (coefficients of variation), using procedures previously described (23). Agarose gel electrophoresis of plasma was carried out in $0.5 \% \mathrm{wt} / \mathrm{vol}$ agarose in barbital buffer ( $\mathrm{pH} 7.4$ ) on strips of polyester film (Gelbond, Bioproducts, Rockland, ME) (26). The strips were fixed in ethanol/acetic acid/water 75:5:20 vol/vol, air-dried, stained in Sudan Black in 60\% ethanol/water (vol/vol), and destained in ethanol/water.

Free (coefficient of variation $=1.2 \%)$ and esterified $(1.0 \%)$ cholesterol, as well as triglyceride $(2.1 \%)$ in plasma and lipoprotein fractions, were measured with standard enzymatic laboratory kits (Boehringer-Mannheim, Germany). Phospholipid $(0.7 \%)$ was measured using a reagent based on phospholipase D and choline oxidase (Biomerieux, Charbonnières les Bains, France). HDL total cholesterol is expressed as the sum of the free and esterified cholesterol in HDL separated from VLDL and $\mathrm{LDL}$ by precipitation with dextran sulfate- $\mathrm{MgCl}_{2}$. Protein $(1.5 \%)$ was determined by the method of Lowry et al. (27).

Other methods. BUN and creatinine were measured using standard automated colorimetric techniques. Hematocrit was determined with a manual microcapillary tube centrifugation technique. Blood glucose was measured with the hexokinase method. Serum total protein was determined by Biuret method.

Data analysis. Statistical analysis was with Student's unpaired $t$ test, unless otherwise specified. Results in the text and tables are expressed as means \pm 1 standard deviation (SD).

\section{Results}

Characterization of study group. Patients in the two treatment groups and the control group were comparable with regard to age, sex distribution, blood pressure, and plasma concentration of total protein, glucose, and triglyceride (Table I). Half of the hemodialysis group had hypertension, which was dialysis-resistant and required one or more drugs for control. The CAPD group had fewer hypertensive patients and only two patients required single-drug treatment. The ESRD patients weighed less than their otherwise matched controls, an observation that has been noted in other studies of the nutritional status of ESRD patients (28). The mean duration of ESRD treatment was not different for the hemodialysis and CAPD groups. Evaluation of dialysis therapy in the two groups revealed that the mean serum creatinine and urea nitrogen values were higher in the hemodialysis patients, whereas hematocrit and plasma glucose values were comparable. Fasting plasma triglyceride concentrations were comparable in all three groups.

The hemodialysis subjects had a significantly lower plasma total and free cholesterol compared to the control group, which was partly reflected by their lower HDL cholesterol. This latter finding is similar to other reports $(9,11)$. The lower phospholipid content in the hemodialysis group can also be explained in part on the basis of the low HDL level. These last three lipid parameters are not significantly different from normal in the CAPD group.

Plasma levels of apo A-I, A-II, B, D, and E of all three groups are shown in Table II. Consistent with the low HDL levels, a greatly reduced apo A-I level was found in the hemodialysis group compared to the control group, whereas the mean value for the CAPD group was intermediate. Apo A-II concentrations were very similar in all three groups. Because different apo AI/A-II ratios have been reported in different HDL subspecies (29), this finding is consistent with reported differences in the HDL subspecies distribution in ESRD patients (13). The levels of apo $\mathrm{E}$ were in the normal range in both ESRD groups, as were the apo B levels. Apo D levels were slightly higher in the ESRD groups as compared with those of the controls.

All subjects had normal plasma glutamic oxaloacetic transaminase and glutamic pyruvic transaminase activities. Three hemodialysis patients showed a double VLDL band on agarose gel electrophoresis; all others in the study had a single VLDL band.

Cholesterol net transport between plasma and cultured cells. The direction and magnitude of cholesterol net transport between

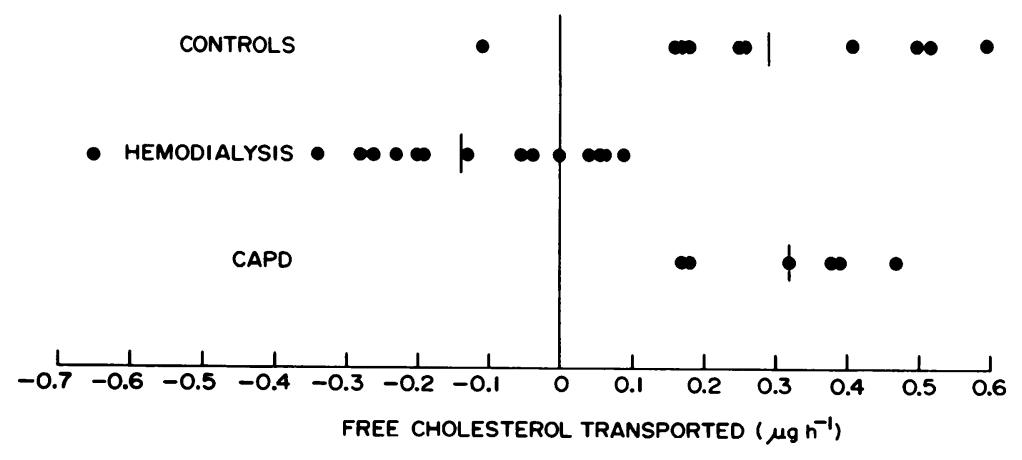

Figure 1. Cholesterol net transport rates between cultured fibroblasts and plasma. Diluted plasma (1.2\% from original) was incubated in the presence or absence of preconfluent human fibroblasts in 6-cm culture dishes containing 8-10 $\mu \mathrm{g}$ of cell sterol for $1 \mathrm{~h}$ at $37^{\circ} \mathrm{C}$. From the difference in the medium's free cholesterol content before and after the incubation, the transport was calculated by subtracting the cholesterol difference in the cell-containing plates from the difference in the empty plates. Consequently, a positive result means a net transport from the cell to the plasma compartment, a negative difference means a reversed transport into the cell. Bar indicates mean value of 15 hemodialysis, 6 CAPD, and 10 control subjects. 
plasma and cultured normal fibroblasts in the ESRD and control groups are shown in Fig. 1. In the control group cholesterol net transport was positive (cells to membrane), indicating a net movement into the plasma compartment from cell membrane cholesterol to compensate for esterification by LCAT (20). The magnitude of such transport $(0.29 \pm 0.22 \mu \mathrm{g} / \mathrm{h})$ is somewhat lower than that of a previous control group $(0.44 \mu \mathrm{g} / \mathrm{h})(1)$, possibly because of their higher mean age ( $52 \mathrm{yr}$ in this study vs. $39 \mathrm{yr}$ earlier), and also because of an unexplained but consistently low cholesterol transport value measured in one of the control subjects. (In a series [ $n=28$ ] of studies of normolipemic, healthy controls [including those in this study], there was in fact an observable correlation $(r=-0.56)$ between cholesterol net transport and age [data not shown].)

However, the cholesterol net transport, obtained from control subjects in the present study, in either case is significantly higher than that found in the hemodialysis group $(-0.14 \pm 0.19 \mu \mathrm{g} / \mathrm{h})$ $(P<0.0005)$. These data indicate that on average the direction of cholesterol net transport in the hemodialysis group is reversed, with entry of free cholesterol from plasma into the cells. On the other hand, cholesterol net transport in the CAPD group was within normal limits $(0.32 \pm 0.12 \mu \mathrm{g} / \mathrm{h})(P>0.25)$ compared to the control group.

It has previously been shown that under the described conditions, the synthesis of cholesteryl ester by normal plasma was not affected by the presence of cells (20). In the present study, there was also no influence of the cholesterol esterification (measured as cholesteryl ester increase) in hemo- and peritoneal dialysis plasma caused by the cells $(0.05<P<0.1, n=21$, paired $t$ test). There was no measurable net transport of cholesteryl ester into or out of hemodialysis plasma, as measured by the cholesteryl ester content of the cells before and after incubation ( $n=11, P>0.25)$.

As with other groups with a reduced or reversed cholesterol net transport $(1,2)$, the ratio of HDL and LDL (expressed here as the ratio between their major apolipoproteins, apo A-I and apo $B$, respectively) was significantly reduced in the hemodialysis group compared with the control group (Table II). Values were intermediate in the CAPD group. However, as noted above, unlike non-insulin-dependent diabetics and those with hyperbeta- or dysbetalipoproteinemia, i.e., other groups with a similar reduction in cholesterol net transport, plasma apo $E$ levels were not significantly increased in the hemodialysis group. In the diabetics, it was shown earlier (2) that removal of apo E from plasma by immunoaffinity chromatography normalized cholesterol net transport, and apo $\mathrm{E}$ in diabetic plasma acted to catalyze

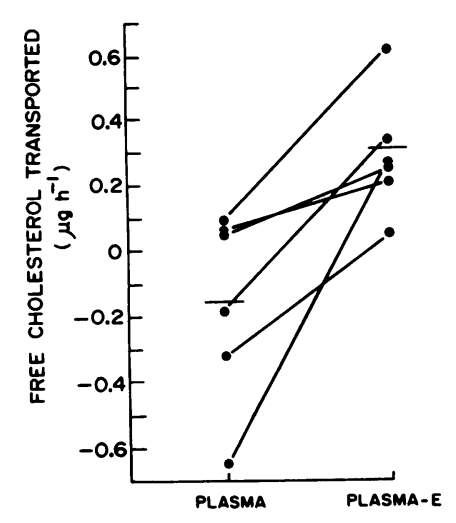

Figure 2. Cholesterol net transport from cultured fibroblasts to medium containing plasma or plasma from which apo $E$ (plasmaE) had been removed by immunoaffinity chromatography $(n=6)$. an increased influx of free cholesterol from diabetic plasma into cells. Despite the normal total plasma apo E level, when apo E was removed from hemodialysis plasma by column chromatography on immobilized anti-E antibody (Fig. 2), there was a significant increase in net transport towards normal levels (mean increase $[0.45 \pm 0.27 \mu \mathrm{g} / \mathrm{h}][n=6])$ compared to unfractionated plasma. This is comparable to the increase $(+0.32 \mu \mathrm{g} / \mathrm{h})$ reported earlier for the diabetic group; removal of apo $\mathrm{E}$ from normal plasma was without detectable effect on transport rates (2). This chromatography led to a $7.2 \pm 0.6 \%$ removal of apo A-I, $13.5 \pm 7.0 \%$ of apo A-II, and $22.9 \pm 7.6 \%$ of apo B from plasma $(n=6)$, which resulted from the binding of intact lipoprotein complexes containing apo $\mathrm{E}$, reflecting the association of apo $\mathrm{E}$ with these apoproteins in HDL and VLDL, respectively (20). $8.0 \pm 2.5 \%$ of free cholesterol, $6.2 \pm 4.2 \%$ of cholesteryl ester, $53.5 \pm 15.5 \%$ of triglycerides, and $18.5 \pm 1.5 \%$ of phospholipids were also bound to the apo $\mathrm{E}$ immunoaffinity column. Therefore, in spite of a normal total plasma apo $\mathrm{E}$ level, hemodialysis plasma showed a similar degree of apo E-dependent inhibition of normal cholesterol net transport as did the plasma of non-insulin-dependent diabetics.

Plasma cholesterol esterification rate. Plasma cholesterol esterification rate was significantly reduced in the hemodialysis group, as compared to normal controls (Fig. 3). The former rate $\left(7.8 \pm 4.3 \mu \mathrm{g}\right.$ of cholesterol esterified $\left.\mathrm{ml}^{-1} \mathrm{~h}^{-1}\right)$ was only about one-third that in the latter group $\left(20.2 \pm 3.7 \mu \mathrm{g} \mathrm{ml}^{-1} \mathrm{~h}^{-1}\right)(P$ $<0.0005$ ).

To determine whether these low activities were the result of a low level of enzyme protein in plasma or a circulating inhibitory factor, cholesterol esterification was also measured by the alternative procedure using an exogenous labeled substrate. As with the assay of endogenous activity in native plasma, the esterification rate of LCAT assayed with liposomes of lecithin and cholesterol was about one-third that found in the normal controls $\left(21.2 \pm 3.1\right.$ vs. $\left.62.5 \pm 0.7 \mu \mathrm{g} \mathrm{ml}^{-1} \mathrm{~h}^{-1}\right)(P<0.0005)$. (The higher rates obtained with the synthetic substrate, which are comparable to those reported earlier [24], probably result from optimization of the lipid composition in the synthetic assay, as compared to that of native lipoprotein substrates.) A second investigation of possible circulating inhibitory factors was made using hemodialysis plasma that had been dialyzed ( $3 \mathrm{~h}$, against $2,000 \mathrm{vol}$ of $0.15 \mathrm{M} \mathrm{NaCl}, 1 \mathrm{mM}$ EDTA, $\mathrm{pH} 7.4,4^{\circ} \mathrm{C}$ ). There was no increase

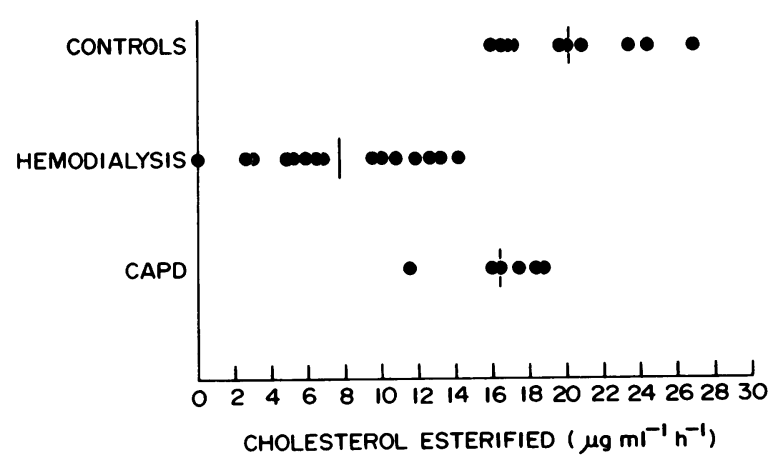

Figure 3. Plasma cholesterol esterification rates in ESRD and control subjects. LCAT activities are expressed as the difference in plasma free cholesterol content before and after a $37^{\circ} \mathrm{C}$ incubation for $1 \mathrm{~h}$. Bar indicates mean value of 15 hemodialysis, $6 \mathrm{CAPD}$, and 10 control subjects. 
in the plasma cholesterol esterification rate in the dialyzed compared to undialyzed plasma $\left(5.6 \pm 2.6 \mu \mathrm{g} \mathrm{m}^{-1} \mathrm{~h}^{-1}\right.$ vs. $4.8 \pm 2.5 \mu \mathrm{g}$ $\mathrm{ml}^{-1} \mathrm{~h}^{-1}$, respectively) $(n=4)$.

Taken together, these data indicate a significantly reduced rate of cholesterol esterification in hemodialysis plasma, which results not from a circulating inhibitor but from a reduction in active circulating LCAT.

The cholesterol esterification rate in CAPD plasma (16.4 \pm 2.9 $\left.\mu \mathrm{g} \mathrm{ml}^{-1} \mathrm{~h}^{-1}\right)$ was slightly lower than in the control group $(0.025$ $<P<0.05)$ and much higher than in the matched hemodialysis group $(P<0.0005)$.

Cholesteryl ester transfer to $V L D L$ and $L D L$. In normolipemic plasma more than one-half of the cholesteryl ester generated by the LCAT reaction is transferred to VLDL and LDL under conditions where LCAT was inhibited $(22,23)$. Such transfer is accompanied by an increase in the cholesteryl ester and a decrease in triglyceride in these lipoproteins $(4,22)$. As shown in Fig. 4, 11.6 $\pm 6.3 \mu \mathrm{g}$ of cholesterol as ester $\mathrm{ml}^{-1} \mathrm{~h}^{-1}$ was transferred to VLDL and LDL in the control group, i.e., $57 \pm 30 \%$ (11.6:20.2) of the total cholesteryl ester synthesized over the same period in native plasma. This proportion is comparable to that in control groups reported earlier $(0.60 ; 0.65)(1,2)$. In the hemodialysis group, however, the cholesteryl ester transfer rate under the same conditions was $2.3 \pm 3.3 \mu \mathrm{g}$ of cholesterol as ester transferred to VLDL and LDL, significantly lower $(P<0.0005)$ than that found in the control group. On average, only $29 \pm 31 \%$ (2.3:7.8) of cholesteryl ester in hemodialysis plasma was transferred to VLDL and LDL $(0.01<P<0.025)$ under these conditions.

Cholesteryl ester transfer to VLDL and LDL was also measured in the dilute plasma used for the determination of cholesterol transport. There was no significant difference $(P>0.25$, $n=6$, paired $t$ test) in cholesteryl ester transfer rates whether or not the cells were present (measurements in three hemodialysis and three control plasmas).

Accordingly, the low rate of transfer seen in hemodialysis plasma could be assigned to two distinct effects: the low rate of cholesteryl esters synthesized by LCAT in hemodialysis plasma, and the ineffective transfer of such esters as were synthesized to VLDL and LDL.

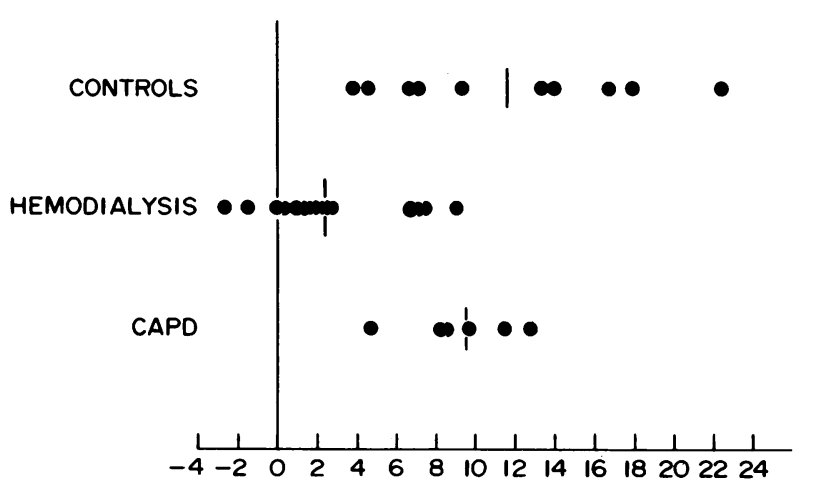

CHOLESTEROL ESTER STEROL TRANSFERRED $\left(\mu \mathrm{g} \mathrm{m}^{-1} \mathrm{~h}^{-1}\right)$

Figure 4. Cholesteryl ester transfer rates in ESRD and control subjects. Transfer activities were determined in terms of the loss of cholesteryl ester from the supernatant HDL fraction after precipitation of VLDL and $\mathrm{LDL}$ with dextran sulfate- $\mathrm{MgCl}_{2}$ during a plasma incubation at $37^{\circ} \mathrm{C}$ for $1 \mathrm{~h}$. Bar indicates mean value of 15 hemodialysis, 6 CAPD, and 10 control subjects.
To determine whether the low transfer rate in hemodialysis plasma was due to a low level of transfer protein or to a circulating inhibitory factor, the activity of transfer was measured in both hemodialysis and control plasma using an exogenous substrate. There was no significant difference in transfer rates between the two groups under these conditions $(21.3 \pm 7.4 \mu \mathrm{g}$ $\mathrm{ml}^{-1} \mathrm{~h}^{-1}$ in the hemodialysis group, and $25.4 \pm 8.9 \mu \mathrm{g} \mathrm{ml}^{-1} \mathrm{~h}^{-1}$ in the control group, $P>0.25(n=4)$. Although the level of HDL cholesterol was lower in the hemodialysis than the control group (Table I), (30 vs. $45 \mathrm{mg} \mathrm{dl}^{-i}$ on average), these differences are unlikely to greatly affect transfer rates (30).

These findings suggest that inhibition of transfer is not mediated primarily by a deficiency of transfer protein, but is caused by an inhibitory factor in plasma. It was shown earlier that diabetic VLDL and LDL inhibited transfer in both diabetic and normal plasma (4). To test the possibility of a similar mechanism in hemodialysis plasma, the nonadsorbed fraction of control plasma from heparin-agarose chromatography was recombined with the adsorbed, dialyzed VLDL + LDL of hemodialysis plasma. As shown in Fig. 5, hemodialysis VLDL and LDL mediated a significantly decreased transfer in control plasma, to a level similar to that found in native hemodialysis plasma. There was little significant change in transfer when control plasma, fractionated in the same way, was recombinant with endogenous VLDL and LDL $(1.03 \pm 0.18, n=3$, relative to transfer in unfractionated native plasma). These data suggest that it is the VLDL and LDL of hemodialysis plasma that are responsible for the inhibition of cholesteryl ester transfer which is observed in the plasma of this group. Cholesteryl ester transfer in the CAPD group (9.4 $\pm 2.9 \mu \mathrm{g} \mathrm{ml}^{-1} \mathrm{~h}^{-1}$, Fig. 4) was not significantly lower than in the normal control group $(P>0.25)$ and was significantly higher than that of the hemodialysis group ( $P$ $<0.0005$ ).

Lipoprotein composition. The lipoprotein compositions of VLDL, LDL, and HDL from the three groups are shown in Table III. As previously reported, a fraction of VLDL not containing apo $\mathrm{E}$ is separated from that VLDL containing bound apo $\mathrm{E}$ during immunoaffinity chromatography on heparin-agarose (4). For all investigated plasmas, an average lipoprotein

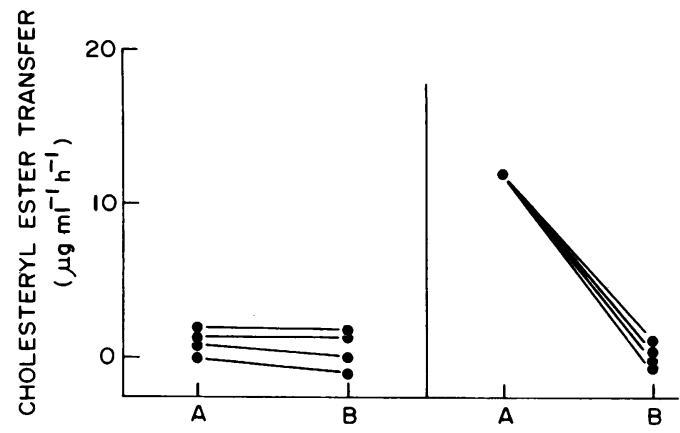

Figure 5. Effects of the recombination of VLDL and LDL from normal plasma (adsorbed fraction from heparin agarose chromatography) with nonadsorbed fraction (containing HDL and all remaining plasma proteins) from four hemodialysis subjects (left), or VLDL and LDL from hemodialysis subjects with HDL from a normal subject (right) on the cholesteryl ester transfer activity. A, whole original plasma; B, recombined plasma. The nonadsorbed and adsorbed fractions were mixed in the original proportion of plasma after exhaustively dialyzing the adsorbed fraction against $0.15 \mathrm{M} \mathrm{NaCl}, 1 \mathrm{mM}$ EDTA, pH 7.4. 


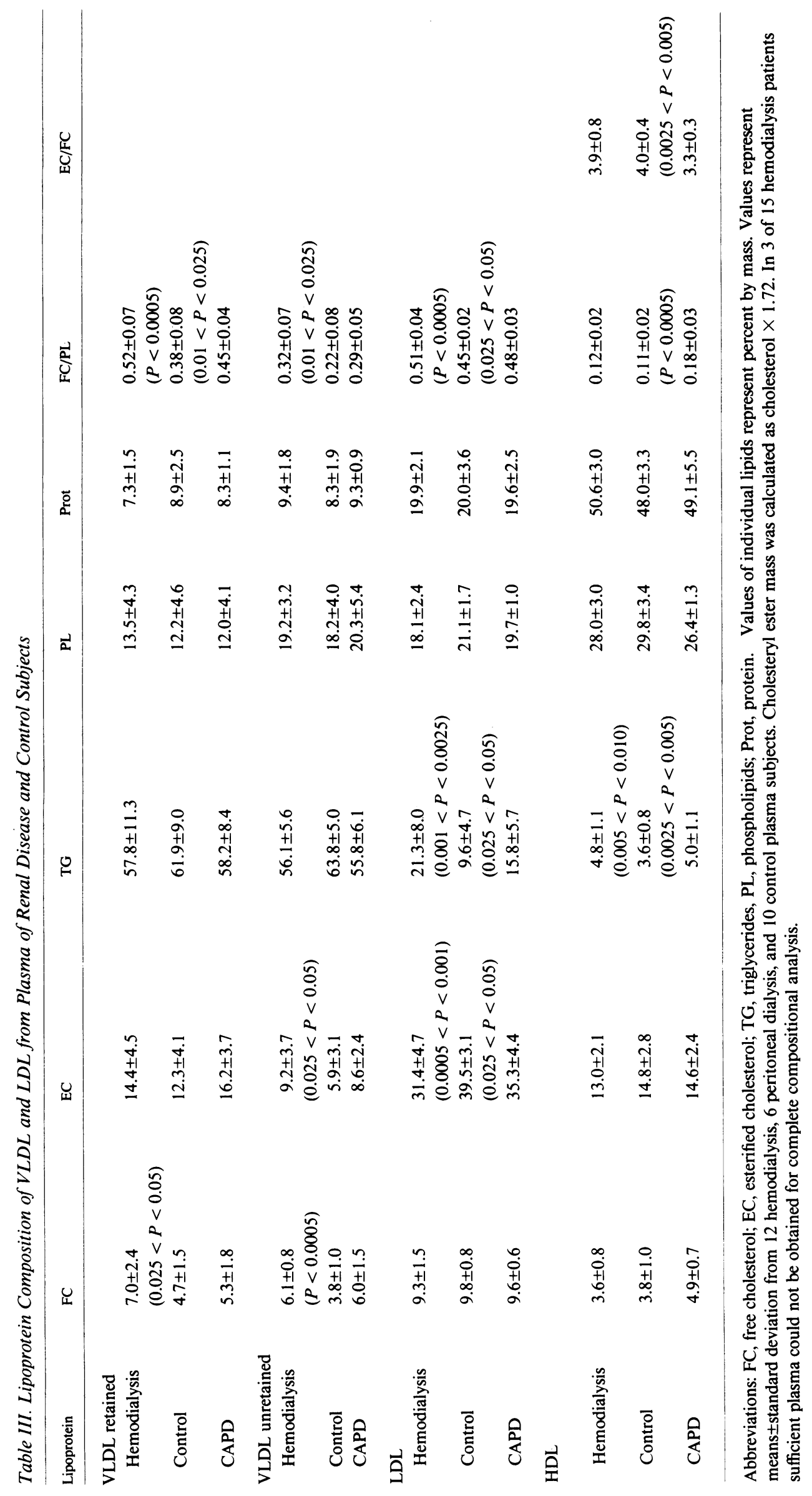


total mass ratio of $2.1 \pm 1.4$ (retained vs. unretained VLDL) was obtained. The protein of the unretained VLDL fraction contained $<0.1 \%$ apo $\mathrm{E}$ (as measured by radial immunodiffusion), which is comparable to previous reports $(31,32)$. Only the latter is retained under the fractionation conditions described here.

The ratios of total lipid to protein in all lipoprotein fractions from all groups were not significantly different $(P>0.25$ in each case). However, the proportions of individual lipids showed several significant differences. In LDL the triglyceride content in the hemodialysis group was more than double that of the control group, whereas it was intermediate in the CAPD group. These changes were accompanied by reciprocal changes in the content of LDL cholesteryl ester. The LDL in the hemodialysis group had significantly less cholesteryl ester than the control group, whereas the value in the CAPD group was intermediate.

The second major difference lay in the ratio of free cholesterol to phospholipid in the hemodialysis VLDL and LDL. As shown in Table III, the ratio of LDL free cholesterol to phospholipid in hemodialysis, CAPD, and control groups was $0.51,0.48$, and 0.45 , respectively. This ratio is significantly higher in the hemodialysis group whereas the difference between the CAPD and control groups is marginal. Similar differences were found among these groups in the two fractions of VLDL, the value of the CAPD being in each case intermediate between the hemodialysis and control groups. In this study, however, whereas the VLDL and LDL that were adsorbed to heparin-agarose had similar ratios of cholesterol to phospholipid, that in the nonadsorbed fraction of VLDL was lower, although the differences among the three experimental groups persisted.

The composition of HDL was similar in the three groups,

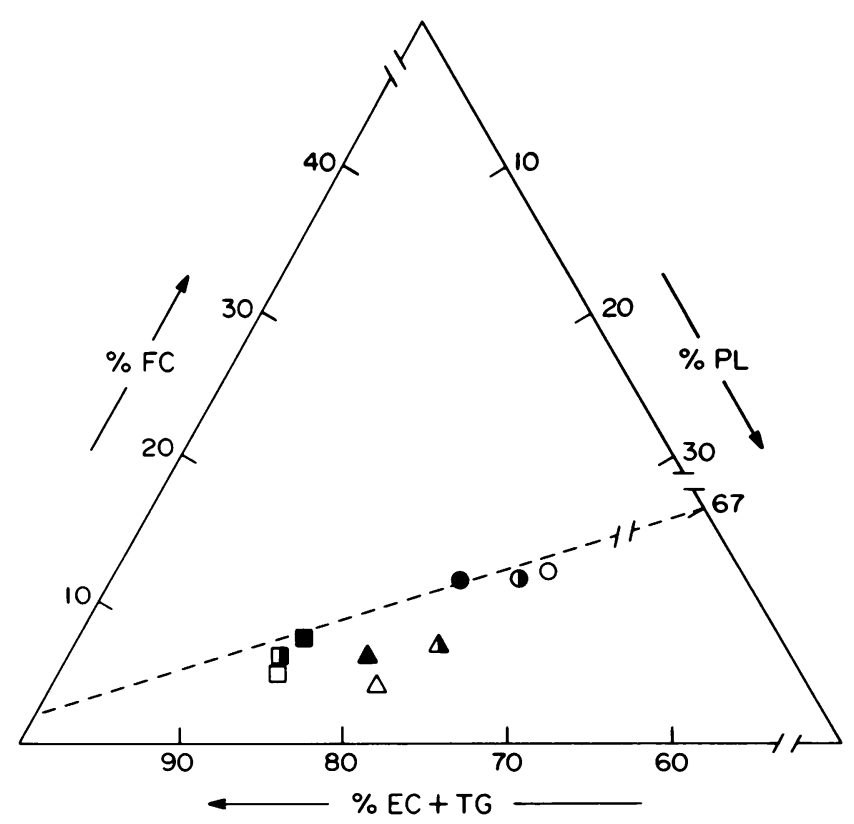

Figure 6. Phase diagram for the lipoprotein average free cholesterol (FC), esterified cholesterol (EC), triglyceride (TG), and phospholipid (PL) moieties of the LDL and VLDL of renal disease and control groups. The dashed line represents the phase boundary above which free cholesterol separates as crystalline phase. Circles, LDL; squares, adsorbed VLDL; triangles, unadsorbed VLDL; open symbols, controls $(n=10)$; solid symbols, hemodialysis group $(n=12)$; half-filled symbols, peritoneal dialysis group $(n=6)$. except for a significantly higher triglyceride content in both treatment groups. The HDL fraction in the CAPD group differed slightly from that of the control group with respect to free cholesterol, phospholipid, and triglyceride content. The ratio of cholesterol to phospholipid was much below that of either VLDL or LDL in the HDL of all the groups; that in the CAPD group, however, was considerably higher than in the control group.

Saturation of free cholesterol in plasma lipoproteins can be expressed in terms of the phase diagram shown in Fig. 6 (33). The average lipid composition of the retained fraction of VLDL and of LDL in the hemodialysis group fell on the phase boundary at which free cholesterol would separate from the particle surface as a crystalline phase. This result indicates that these lipoproteins can be considered as saturated with cholesterol in the hemodialysis subjects. The lipoproteins of both CAPD and control groups, on the other hand, show a composition indicating a lower surface content of free cholesterol. The nonadsorbed (apo $E$ free) fraction of VLDL, in contrast to the earlier finding with diabetics (4), showed a lower free cholesterol content in all the groups and because of its lower free cholesterol content, fell below the phase line seen in the hemodialysis plasma. However, as previously shown (4), this fraction is inactive in transfer, both in normal and diabetic plasma.

In order to rule out possible effects of the various medications administered, most of the lipid and lipoprotein parameters were grouped accordingly, as shown in Table IV. A few parameters like apo A-II, free cholesterol, HDL cholesterol, and triglyceride reached significant differences between the different groups, most others were not significantly influenced by the different drugs $(P>0.05)$.

\section{Discussion}

There is now considerable evidence that a reaction sequence involving the transport of cholesterol from cell membrane to plasma, its esterification, and finally its transfer to VLDL and LDL plays an important part in the cholesterol homeostasis of peripheral cells $(1,2)$. A key component of this sequence is the chemical potential gradient of free cholesterol between cell membranes and plasma which is maintained by the LCAT reaction (20). When the rate of cholesterol esterification by LCAT is decreased, either synthetically with a suitable inhibitor or physiologically as a result of primary LCAT deficiency, the net transport of cholesterol from cells to plasma is inhibited (34). Inhibition of a different kind results from an increase in the cholesterol content of the lipoproteins in the plasma compartment. In this case the concentration gradient of cholesterol, even in the presence of normal levels of LCAT, becomes more shallow or may even be reversed. As a result, instead of cholesterol being transported from cells to plasma, cholesterol is driven from plasma into the cells. High free cholesterol levels in plasma also appear to mediate a second and apparently distinct effect. Saturation of free cholesterol levels at the surface of VLDL and LDL is accompanied by an inhibition of cholesteryl ester transfer to these lipoproteins in the same plasma.

The results in this study indicate that, uniquely in hemodialysis patients, both mechanisms of inhibition of normal cholesterol transport (a primary LCAT deficiency and a reversed free cholesterol concentration gradient) are operative. As a result, cholesterol transport in the plasma of these subjects is grossly 


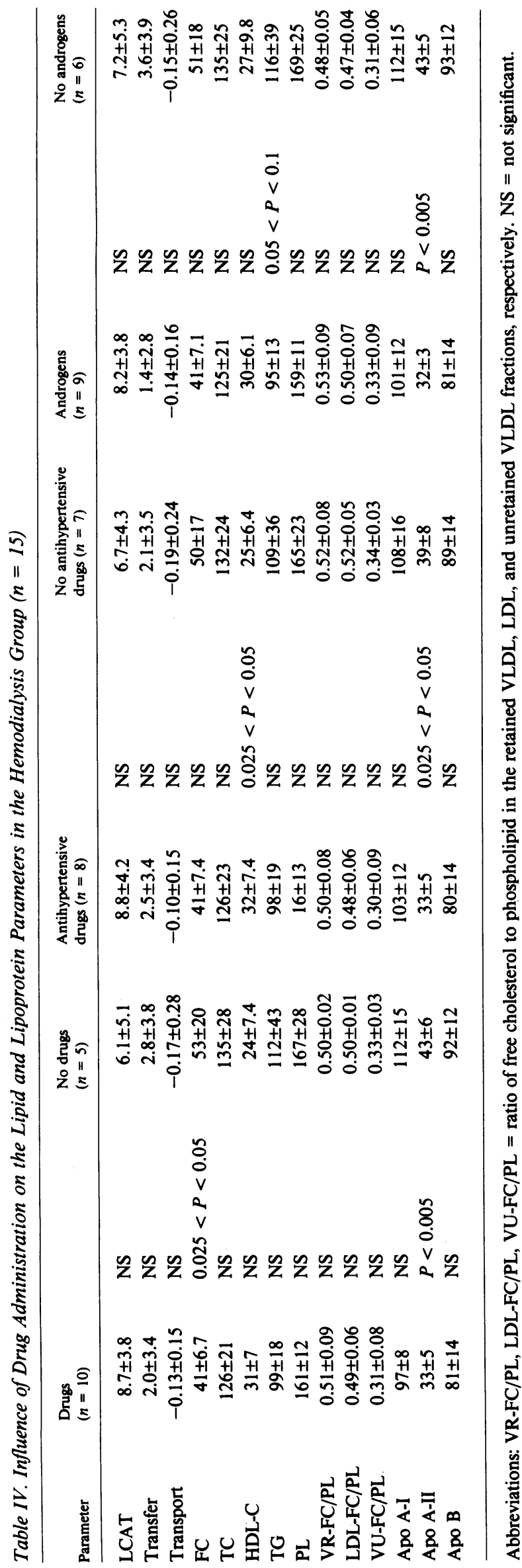

inhibited. The evidence is as follows: Hemodialysis subjects had a significantly reduced rate of cholesterol esterification in plasma, a finding previously noted in undialyzed uremic patients (19). This lower rate appears to be a function of a lower level of catalytically active LCAT in the plasma of these subjects than in the group with normal renal function, in that the esterification rate in hemodialyzed plasma is not normalized, even after dialysis or in the presence of reactive substrate lipoproteins. As a result, the total utilization of free cholesterol in hemodialyzed plasma is about one third of normal.

The decrease in net transport might be due to the decreased demand of free cholesterol by the LCAT reaction. However, an additional factor must be operative here, because mean cholesterol net transport levels are reduced not only from the normal mean of +0.29 to a predicted $+0.1 \mu \mathrm{g} / \mathrm{h}$ (the product of 0.29 and the ratio of cholesterol esterification rates in the hemodialysis and control plasma, i.e., $0.29 \times 7.8 / 20.2$ ), but are more severely reduced, even reversed, in the hemodialysis group to an average level of $-0.14 \mu \mathrm{g} / \mathrm{h}$. The concept that LCAT is not the only determinant of cholesterol transport in these patients is supported by the lack of significant correlation in the hemodialysis group between cholesterol transport and esterification rates $(r=-0.30$, $0.1<P<0.25, n=15$ ).

Several pieces of evidence suggest that the increased saturation of free cholesterol in VLDL and LDL in the hemodialysis plasma is particularly important in mediating the abnormalities of plasma cholesterol metabolism that have been observed. First, transfer of cholesteryl ester to VLDL and LDL in the hemodialysis group is significantly reduced. Actually, the mean value for the cholesteryl ester transfer in the hemodialysis group indicates that there is almost no such transfer to the VLDL and LDL fractions, and even the decreased amount of esters formed by the LCAT reaction is retained almost quantitatively in HDL. In non-insulin-dependent diabetes, an increased concentration of triglyceride and decreased concentration of cholesteryl ester were seen in LDL where transfer was inhibited (4). However, these studies involved plasma in which total plasma triglyceride was also increased, so that the association between transfer and composition was necessarily indirect. On the other hand, in the current hemodialysis patients, whose plasma triglyceride levels were comparable to those of the control group, the increased level of triglyceride in LDL was compatible with the inhibition of transfer observed in native hemodialysis plasma, although other explanations are also possible. This interpretation is supported by the comparison between the mass difference in triglyceride and cholesteryl ester transfer seen in the hemodialysis and control LDL. The increment of triglyceride in the former group $(+11.7 \%)$ is clearly proportional to the decrease in cholesteryl ester $(-8.1 \%)$ when the difference in lipid molecular weights (triglyceride $=880$, cholesteryl ester $=663$ ) is taken into account. It has been shown elsewhere that the catalyzed transfer of cholesteryl ester is accompanied by equimolar back-transport of triglyceride (4).

A second piece of evidence linking the inhibition of transfer to that of cholesterol transport is obtained from the reconstitution experiments with hemodialysis VLDL and LDL with the nonadsorbed fraction from the affinity chromatography of normal plasma. The hemodialysis cholesteryl ester acceptor lipoproteins inhibited transfer in normal plasma to a level similar to that observed in native hemodialysis plasma. This finding indicates that a major factor inhibiting transfer, as in diabetic plasma, involves the composition of VLDL and LDL. A slight, though 
probably undetectable, increase of cholesteryl ester transfer rate would have been predicted when the VLDL and LDL fractions of the hemodialysis plasma were replaced by those of normolipemic plasma, because of the expected normalization of the acceptor properties for the cholesteryl esters to be transferred, i.e., the difference between the hemodialysis transfer rates $(2.3$ $\left.\mu \mathrm{g} \mathrm{ml}^{-1} \mathrm{~h}^{-1}\right)$ and $57 \%$ of their LCAT rates $\left(4.5 \mu \mathrm{g} \mathrm{ml}^{-1} \mathrm{~h}^{-1}\right.$, the measured mean proportion of LCAT-derived cholesteryl esters transferred into VLDL and LDL in the control group).

Finally, the acceptor lipoproteins of hemodialysis plasma, by direct chemical analysis, showed significantly higher ratios of free cholesterol to phospholipid, such that these particles were essentially saturated with free cholesterol. All these data are consistent with the concept that it is the abnormally high ratio of free cholesterol to phospholipid in the VLDL and LDL fractions of hemodialysis plasma that is the second factor mediating the reversal of cholesterol net transport in the hemodialysis patient. The rate of cholesteryl ester transfer in hemodialysis plasma is inversely correlated $(r=-0.66, n=12,0.005<P<0.010)$ with the free cholesterol/phospholipid ratio of LDL, the major acceptor of such esters. Cholesterol net transport between cell membranes and hemodialysis plasma is also correlated with the LDL free cholesterol/phospholipid ratio $(r=-0.64, n=12$, $0.010<P<0.025)$. These data are together compatible with the concept that it may be the increased free cholesterol content of the acceptor lipoproteins of hemodialysis plasma that is the major factor inhibiting cholesteryl ester transfer in hemodialysis plasma.

Interestingly, comparison of the HDL fraction of the hemodialysis plasma with that of the control group showed relatively small differences in composition (with the exception of an increased triglyceride content in the hemodialysis group). However, the recovery of cholesteryl esters in HDL during assay of transfer in hemodialysis plasma is not quantitatively greater (the difference between LCAT and transfer rates in both groups, or $6.5 \mu \mathrm{g} \mathrm{ml}^{-1}$ plasma h $\mathrm{h}^{-1}$ for the dialysis subjects vs. $8.6 \mathrm{~g} \mathrm{ml}^{-1}$ plasma $\mathrm{h}^{-1}$ for the control group). This suggests that the composition of $\mathrm{HDL}$ is not rate-limiting for transfer in renal failure.

A second feature of the present study is the similarity of the metabolic defect found here in hemodialysis plasma to that found in other patient groups also at increased risk of atherosclerotic vascular disease $(1,2,4)$. In addition to the abnormalities of cholesteryl ester transfer and cholesterol transport described above, which are shared with non-insulin-dependent diabetics and with several well-defined hyperlipidemic groups, the abnormal transport of cholesterol in hemodialysis plasma was apo E-dependent as was that of the diabetics, in spite of the normal level of total apo $\mathrm{E}$ in the hemodialysis group. Removal of apo E by immunoaffinity chromatography resulted in a significant normalization of transport in these patients. This suggests that a fraction of apo $\mathrm{E}$ with abnormal metabolic properties, rather than an increased level of apo E per se, catalyzes the increased flux of free cholesterol from plasma to cell membranes that characterizes the affected groups. These data seem most compatible with the concept proposed earlier (35) that those at increased risk for atherosclerotic vascular disease share a common metabolic defect that is related to the higher ratio of free cholesterol to phospholipids in VLDL and LDL.

A final feature of this study lies in the significant difference between the biochemical and metabolic properties of plasma from ESRD patients treated by hemodialysis or by CAPD. In each of the metabolic factors studied, the plasma of peritoneal dialysis patients showed significantly less abnormality than did the plasma from the hemodialysis group. Some of the parameters, such as plasma cholesterol esterification, transfer of the cholesteryl esters, and cholesterol transport rates showed values within normal limits, whereas others, such as HDL cholesterol and the plasma apo A-I/A-II ratios were found to be intermediate between those of the hemodialysis and the control groups. The reason for these significant differences between the patient groups is not readily apparent. Previous studies of plasma lipid levels in CAPD patients have found elevated plasma triglycerides in $40-50 \%$ of patients, a greater incidence of elevated total cholesterol levels than in the hemodialysis population, and a low normal to depressed HDL cholesterol fraction $(14,17,36)$. The normal triglyceride and total cholesterol levels in the CAPD group in these studies may reflect a healthier subgroup, identified by the selection criteria for this protocol, in that the overall CAPD population from which they were selected has an incidence of hypertriglyceridemia and hypercholesterolemia of $47 \%$. However, the striking differences between the hemodialysis and CAPD patients cannot be explained on this basis, because both were selected by the same criteria. Possible factors that may influence these differences include $(a)$ the medical status of the patient, $(b)$ adequacy of dialysis therapy, $(c)$ nutritional factors, and $(d)$ drug therapy. The medical status of the patient with regard to etiology of renal disease and the presence of hypertension and other complications of uremia is known to be an important determinant of morbidity and survival in ESRD patients. Important characteristics of CAPD therapy that may affect the differences seen in these patient groups include $(a)$ the inherently greater peritoneal dialysis transport of larger molecular weight compounds, $(b)$ removal of larger quantities of body proteins, (c) better control of extracellular fluid volume, and $(d)$ steadystate biochemical control without the daily fluctuations associated with hemodialysis therapy. In addition, the CAPD patients in this study were better dialyzed as reflected by mean BUN and creatinine concentrations, although the actual differences were rather small. It is possible that the more efficient removal of a retained toxin in the CAPD group could positively affect cholesterol metabolism in these patients. The nutritional status of these groups reflects the previously documented mild reduction of total protein and albumin in CAPD patients secondary to dialysate protein loss. Nutrient intake was not specifically measured in either patient group, but could be expected to include a higher intake of carbohydrate due to dialysate glucose, and a higher prescribed protein intake for the CAPD patients. Both of these factors have been implicated in the pathogenesis of the hyperlipidemia observed in CAPD patients, but would not explain why this subset of patients had relatively normal cholesterol metabolism, compared to the hemodialysis group.

Drug therapy differed in the two patient groups due to the presence of dialysis-resistant hypertension in 8 of 15 hemodialyzed patients, but only 2 of 6 CAPD patients. Six of the hypertensive patients were treated with beta blockers, which have been shown to have unfavorable effects on plasma lipid composition, including an elevation in LDL and VLDL cholesterol and a decrease in HDL cholesterol (37). However, it is unlikely that the differences between hemodialysis and CAPD patients were due to antihypertensive drug therapy, because the abnormalities in cholesterol metabolism in the hemodialysis group were equally present in both drug treated and untreated patients.

The clinical relevance of these studies is potentially very high. The high mortality rate from atherosclerotic vascular disease is 
well documented, although the specific risk factors or mechanisms which are responsible for this disease remain less clearly identified $(5,6)$. There has been repeated documentation of abnormal triglyceride metabolism in ESRD patients, but the importance of this factor in the pathogenesis of atherosclerosis is controversial (10-12). These studies provide strong evidence that, despite normal total plasma triglyceride and cholesterol levels, some dialysis patients have a striking defect in cholesterol metabolism, which could play an important role in the pathogenesis of vascular disease in these patients. The observation, albeit in a small number of patients, that peritoneal dialysis may protect against this defect also has potentially important implication for the selection of a long-term ESRD therapy modality.

It is to be emphasized that the present data are derived from measurements made in vitro, although the assays involved have been well validated over a period of time with a number of patient and normal control groups. However, the implication of these results, taken together with those previously reported with other patient groups, is that patients with ESRD treated by CAPD appear to have lower rates of accumulation of free cholesterol in peripheral tissues than those treated by hemodialysis, and that this might result in a lower incidence of atherosclerotic vascular disease.

\section{Acknowledgments}

We acknowledge the expert technical assistance of Mercedita Rosario, Elaine Hoye, and Mary Fisher. We thank Dr. William Amend, Jr. for allowing us to study a patient under his care, as part of this investigation.

This research was supported by the National Institute of Health through Arteriosclerosis SCOR Programs HL-14237 and HL-23738, and by grants from the Max Kade Foundation, Inc., New York, and the Oesterreichische Bundeshandelskammer, Austria. Dr. Dieplinger is a postdoctoral fellow of the University of Graz, Austria.

\section{References}

1. Fielding, P. E., C. J. Fielding, R. J. Havel, J. P. Kane, and P. Tun. 1983. Cholesterol net transport, esterification and transfer in human hyperlipidemic plasma. J. Clin. Invest. 71:449-460.

2. Fielding, C. J., G. M. Reaven, and P. E. Fielding. 1982. Human non-insulin dependent diabetes: identification of a defect in plasma cholesterol transport normalized in vivo by insulin and in vitro by selective immunoadsorption of apolipoprotein E. Proc. Natl. Acad. Sci. USA. 79: 6365-6369.

3. Schernthaner, G., G. M. Kostner, H. Dieplinger, R. Prager, and I. Muelhauser. 1983. Apolipoproteins (A-I, A-II, B), Lp(a) lipoprotein and lecithin:cholesterol acyltransferase activity in diabetes mellitus. Atherosclerosis. 49:277-293.

4. Fielding, C. J., G. M. Reaven, G. Liu, and P. E. Fielding. 1984. Increased free cholesterol in plasma low and very low density lipoprotein in non-insulin dependent diabetes mellitus: its role in the inhibition of cholesteryl ester transfer. Proc. Natl. Acad. Sci. USA. 81:2512-2516.

5. Green, D., N. J. Stone, and F. A. Krumlovsky. 1983. Putative atherogenic factors in patients with chronic renal failure. Prog. Cardiovasc. Dis. 26:133-144.

6. Lowrie, E. G., J. M. Lazarus, C. L. Hampers, and J. P. Merrill. 1974. Cardiovascular disease in hemodialysis patients. N. Engl. J. Med. 290:737-738.

7. Lindner, A., B. Charra, D. J. Sherrard, and B. H. Scribner. 1974. Accelerated atherosclerosis in prolonged maintenance hemodialysis. $N$. Engl. J. Med. 290:697-701.
8. Rostand, S. G., J. C. Gretes, K. A. Kirk, E. A. Butsky, and T. E. Andreoli. 1979. Ischemic heart disease in patients with uremia undergoing maintenance hemodialysis. Kidney Int. 16:600-611.

9. Rapaport, J., M. Aviram, C. Chaimovitz, and J. G. Brook. 1978. Defective high density lipoprotein composition in patients on chronic hemodialysis. N. Engl. J. Med. 29:1326-1329.

10. Bagdade, J. D., D. Porte, and E. L. Bierman. 1968. Hypertriglyceridemia: a metabolic consequence of chronic renal failure. $N$. Engl. J. Med. 279:181-185.

11. Brunzell, J. D., J. J. Albers, L. B. Haas, A. P. Goldberg, L. Agadoa, and D. J. Sherrard. 1977. Prevalence of serum lipid abnormalities in hemodialysis. Metab. Clin. Exp. 26:903-910.

12. Nestel, J. P., N. H. Fidge, and M. H. Tan. 1982. Increased lipoprotein remnant formation in chronic renal failure. $N$. Engl. J. Med. 307:329-333.

13. Goldberg, A. P., H. R. Harter, W. Patsch, K. B. Schechtman, M. Province, C. Weerts, I. Kuisk, M. M. McCrate, and G. Schonfeld. 1983. Racial differences in plasma high-density lipoproteins in patients receiving hemodialysis: a possible mechanism for accelerated atherosclerosis in white men. N. Engl. J. Med. 308:1245-1252.

14. Ramos, J. M., R. Gokal, K. Siamopolous, M. K. Ward, R. Wilkinson, and D. N. S. Kerr. 1983. Continuous ambulatory peritoneal dialysis: three years experience. Q. J. Med. 52:165-186.

15. Glasson, P., M. Leski, and H. Favre. 1981. Dialyse peritoneale chronique ambulatoire. Schweiz. Med. Wochenschr. 111:1232-1238.

16. Roncari, D. A. K., W. C. Beckenridge, and R. Khanna. 1981. Rise in high density lipoprotein cholesterol in some patients treated with CAPD. Periton. Dial. Bull. 1:136-137.

17. Cantaluppi, A., A. Scalamogna, L. Guerra, G. Graziani, and C. Ponticelli. 1982. Plasma lipid and lipoprotein levels in patients treated with CAPD. Periton. Dial. Bull. 2:99.

18. Ramos, J. M., A. Heaton, J. G. McGurk, M. K. Ward, and D. N. S. Kerr. 1983. Sequential changes in serum lipids and their subfractions in patients receiving continuous ambulatory peritoneal dialysis. Nephron. 35:20-23.

19. Guarnieri, G. F., M. Moracchiello, L. Campanacci, F. Ursini, L. Ferri, M. Valente, and C. Gregolin. 1978. Lecithin:cholesterol acyltransferase (LCAT) activity in chronic uremia. Kidney Int. 13(Suppl. 8):2630.

20. Fielding, C. J., and P. E. Fielding. 1981. Evidence for a lipoprotein carrier in human plasma catalyzing sterol efflux from cultured fibroblasts and its relationship to lecithin:cholesterol acyltransferase. Proc. Natl. Acad. Sci. USA. 78:3911-3914.

21. Heider, J. G., and R. L. Boyett. 1978. The picomole determination of free and total cholesterol in cells in culture. J. Lipid Res. 19:514-518.

22. Aron, L., S. Jones, and C. J. Fielding. 1978. Human plasma lecithin:cholesterol acyltransferase: characterization of cofactor dependent phospholipase activity. J. Biol. Chem. 253:7220-7226.

23. Fielding, P. E., and C. J. Fielding. 1980. A cholesteryl ester transfer complex in human plasma. Proc. Natl. Acad. Sci. USA. 77:3327-3330.

24. Fielding, C. J., and P. E. Fielding. 1981. Regulation of human plasma lecithin:cholesterol acyltransferase activity by lipoprotein acceptor cholesteryl ester content. J. Biol. Chem. 256:2102-2104.

25. Ogawa, Y., and C. J. Fielding. 1984. Assay of cholesteryl ester transfer activity and purification of a cholesteryl ester transfer protein. Methods Enzymol. 111:274-285.

26. Pagnan, A., R. J. Havel, J. P. Kane, and L. Kotite. 1977. Characterization of human very low density lipoprotein containing two electrophoretic populations: double prebetalipoproteinemia and primary dysbetalipoproteinemia. J. Lipid Res. 18:613-622.

27. Lowry, O. H., N. J. Rosebrough, A. L. Farr, and R. J. Randall. 1951. Protein measurement with the Folin phenol reagent. J. Biol. Chem. 193:265-275. 
28. Schoenfeld, P. Y., R. R. Henry, N. M. Laird, and D. M. Roxe. 1983. Assessment of nutritional status of the national cooperative dialysis study population. Kidney Int. 23(Suppl. 13):80-81.

29. Cheung, M. C., and J. J. Albers. 1977. The measurement of apolipoproteins A-I and A-II levels in men and women by immunoassay. J. Clin. Invest. 60:43-50.

30. Ihm, J., D. M. Quinn, S. J. Busch, B. Chataing, and J. A. K. Harmony. 1982. Kinetics of plasma protein-catalyzed exchange of phosphatidylcholine and cholesteryl ester between plasma lipoproteins. $J$. Lipid Res. 23:1328-1341.

31. Trezzi, E., C. Calvi, P. Roma, and A. L. Catapano. 1983. Subfractionation of human very low density lipoproteins by heparinsepharose affinity chromatography. J. Lipid Res. 24:790-795.

32. Shelburne, T. A., and S. H. Quarfordt. 1977. The interaction of heparin with an apoprotein of human very low density lipoprotein. $J$. Clin. Invest. 60:944-950.
33. Miller, K. W., and D. M. Small. 1983. Surface-to-core and interparticle equilibrium distributions of triglyderice-rich lipoprotein lipids. J. Biol. Chem. 258:13772-13784.

34. Fielding, C. J., J. Frohlich, K. Moser, and P. E. Fielding. 1982. Promotion of sterol efflux and net transport by apolipoprotein $\mathrm{E}$ in lecithin:cholesterol acyltransferase deficiency. Metab. Clin. Exp. 31:10231028.

35. Fielding, C. J. 1984. The origin and properties of free cholesterol potential gradients in plasma, and their relation to atherosclerosis. $J$. Lipid Res. 25:1624-1628.

36. Lipid Research Clinics Program Epidemiology Committee. 1979. Plasma lipid distributions in selected North American populations: the Lipid Research Clinics Program Prevalence Study. Circulation. 60:427439.

37. Flamenbaum, W. 1983. Metabolic consequences of antihypertensive therapy. Ann. Intern. Med. 92:875-880. 